\title{
Sequence and Structural Organization of Murine Cytomegalovirus Immediate-Early Gene 1
}

\author{
GÜNTHER M. KEIL, ANGELIKA EBELING-KEIL, AND ULRICH H. KOSZINOWSKI* \\ Federal Research Centre for Virus Diseases of Animals, D-7400 Tübingen, Federal Republic of Germany
}

Received 10 December 1986/Accepted 3 March 1987

\begin{abstract}
In murine cytomegalovirus, abundant immediate-early transcription originates from 0.769 to 0.815 map units of the genome. This region contains the immediate-early gene (gene ieI) which encodes pp89, a phosphoprotein active in transcriptional regulation. In this paper we report on the precise location, structural organization, and sequence of gene $i e I$. The predominant $i e I$ transcript, a 2.75-kilobase mRNA, is generated by splicing and composed of four exons. The precise termini of the 2.75-kilobase mRNA and the positions of the exons were determined by nuclease digestion experiments with either $5^{\prime}$ or $3^{\prime}$ end-labeled DNA fragments or in vitro transcribed cRNA probes. Exons of 300,111, 191, and 1,703 nucleotides are separated by introns of 825, 95, and 122 nucleotides. The first AUG is located in the second exon of 111 nucleotides, and a single open reading frame of 1,785 nucleotides predicts a protein of 595 amino acids with a calculated molecular weight of 66,713. The $\mathrm{N}$-terminal region of the protein contains sequences similar to a consensus sequence of histone $2 \mathrm{~B}$ proteins. The regulatory function of $\mathrm{pp89}$ and the role of this protein as an immunodominant antigen are discussed in relation to the amino acid sequence.
\end{abstract}

As with other herpesviruses, expression of murine cytomegalovirus (MCMV) genes in infected cells is temporally controlled and regulated in a cascade fashion (7). In the absence of protein synthesis, predominant transcription occurs from three immediate-early (IE) transcription units designated ie1, ie2, and ie 3 (10). IE proteins are the first proteins synthesized after infection or reactivation from latency. At least one herpesviral IE protein is required for synthesis of early and late mRNAs. The dominant IE protein of MCMV could be identified as a phosphoprotein (12) with an apparent molecular weight of 89,000 (pp89). Expression of pp89 encoded by gene ieI contained in transcription unit 1 is under control of a complex enhancer sequence (2). Functional analysis revealed that, after transient expression or stable transfer of ie1 into fibroblasts, pp89 activates heterologous promoters (14). Transactivation as a function of herpesviral IE proteins has also been demonstrated for ICP4, the major IE protein of herpes simplex virus type 1 , and the major IE proteins of human cytomegalovirus (HCMV), pseudorabies virus, and varicella-zoster virus (4). Analysis of the different regulatory genes and comparison of the different proteins should help us to understand the mechanism by which this activation is achieved.

Other studies focused on the property of MCMV proteins as target structures for the protective immune response of the host $(30,31,33)$. Viral antigens of the IE phase were detected which are recognized by cytolytic $\mathrm{T}$ lymphocytes (CTL) (31). Cells with specificity for MCMV IE antigens constitute the major proportion of MCMV-specific CTL (31). In subsequent studies we could demonstrate that (i) IE antigen presentation for CTL throughout the replication cycle correlates with the synthesis of pp89 (29) and (ii) cells that express pp89 after IE gene transfection are lysed by cloned MCMV IE antigen-specific CTL $(15,28)$.

A viral protein active in gene regulation should contain signals for nuclear transport, whereas viral antigen recognition by CTL requires the presence of the antigen at the plasma membrane. It was of interest to learn whether

* Corresponding author. analysis of the sequence of the gene would explain how these two requirements are fulfilled. In this paper we present the physical organization, as well as the deduced amino acid sequence and secondary structure, of pp89 and the complete nucleotide sequence of $i e \mathrm{I}$. The relation of the $i e \mathrm{I}$ gene to other known herpesviral IE genes and membrane expression of the protein are discussed.

\section{MATERIALS AND METHODS}

Virus and cell culture. MCMV (Mouse salivary gland virus, strain Smith, ATCC VR-194) was propagated on $\mathrm{BALB} / \mathrm{c}$ mouse embryo fibroblasts as previously described (3).

Isolation of IE RNA. Mouse embryo fibroblasts were infected with MCMV at a multiplicity of 20 to 40 PFU per cell in the presence of cycloheximide $(50 \mu \mathrm{g} / \mathrm{ml})(11)$. Preparation of whole-cell RNA and selection of poly(A) ${ }^{+}$RNA by oligo(dT)-cellulose chromatography were carried out as described previously (11).

Cloning of DNA. Recombinant plasmids were prepared by published procedures (20). BAL 31 treatment and generation of blunt ends with the Klenow polymerase were as previously described (20).

Analysis of RNA. IE RNA $(5 \mu \mathrm{g})$ was either (i) hybridized to 0.03 to 0.1 pmol of end-labeled MCMV DNA fragments and then digested with $S 1$ nuclease (2) or (ii) hybridized to $2 \times 10^{5} \mathrm{cpm}$ of uniformly labeled cRNA, transcribed by the SP6 RNA polymerase, and then digested with RNase A and RNase T1 as previously described (23). Nuclease-resistant fragments were size fractionated on denaturing sequencing gels.

Labeling, strand separation, and sequence analysis of DNA. End labeling of cloned DNA fragments and preparation of uniquely labeled fragments by strand separation or secondary restriction enzyme cleavage were performed as previously described (20). DNA sequence analysis was done by the method of Maxam and Gilbert (21), except that the A+G modification reaction was $3 \mathrm{~min}$ at $22^{\circ} \mathrm{C}$ in $70 \%$ formic acid. 


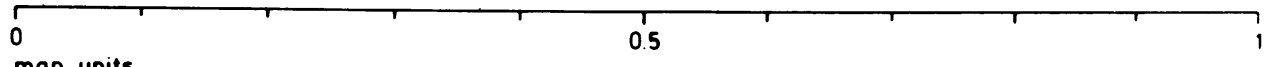

map units

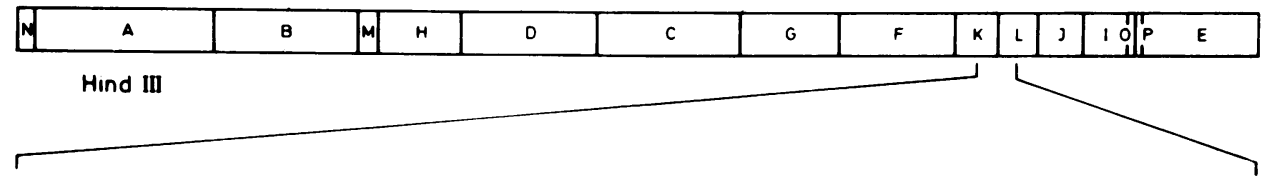

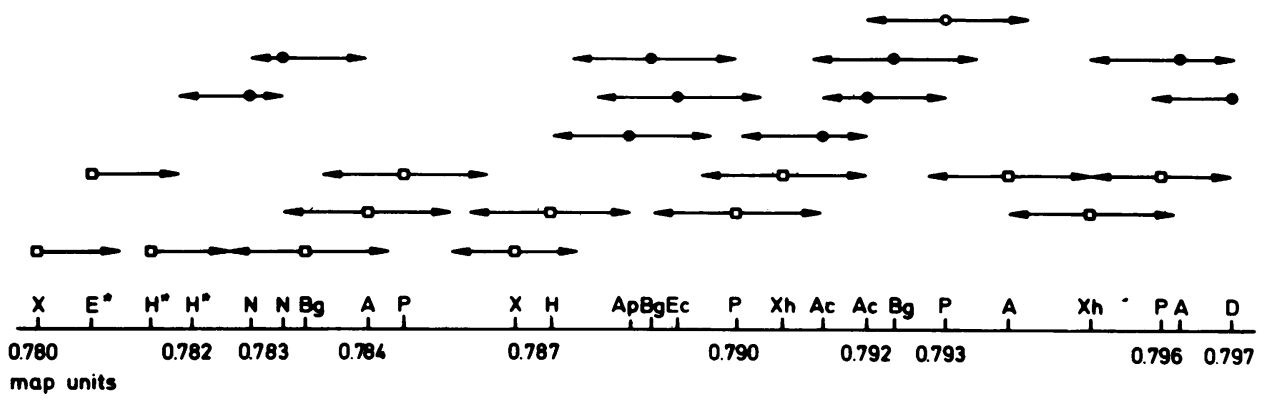

FIG. 1. HindIII cleavage map of the MCMV genome and sequencing strategy for $i e I$. The region between map units 0.780 and 0.797 is expanded. Restriction enzyme cleaveage sites used for DNA sequencing are shown. DNA fragments labeled at the $5^{\prime}$ or $3^{\prime}$ end were sequenced as indicated by the arrows. Arrows connected by open squares represent fragments analyzed with both $5^{\prime}$ and $3^{\prime}$ labeled ends. Open circles indicate fragments analyzed after 3' labeling, and closed circles indicate fragments analyzed after 5' labeling. Abbreviations: A, Asp718; Ac, AccI; Ap, ApaI; Bg, BlgII; D, DraI; E, EcoRI; Ec, EcoRV; H, HindIII; N, NcoI; P, PstI; X, XbaI; Xh, XhoI. The EcoRI and HindIII sites marked with asterisks were introduced by insertion of synthetic linkers after BAL 31 digestion from the $X b a I$ site ( $\left.E^{*}\right)$ at map unit 0.780 or the $N c o I$ site $\left(\mathrm{H}^{*}\right)$ at map unit 0.783 .

\section{RESULTS}

Nucleotide sequence of MCMV ieI. The 5' cap site of the 2.75-kb mRNA was located at a position 280 nucleotides ( $\mathrm{n}$ ) upstream of the XhoI site at map unit 0.795 (2) (Fig. 1). RNase protection experiments with cRNA transcribed in vitro by SP6 polymerase from the $P$ stI site ( 0.796 map units) to the DraI cleavage site (0.797 map units) confirmed the start position at $50 \mathrm{n}$ upstream of the Pst I site $(0.796$ map units). Transcription of $i e I$ terminates to the right of map position 0.781 (10), and because cloned DNA from map units 0.780 to 0.782 did not select $i e I$-specific mRNA (unpublished data), the $3^{\prime}$ end of the $2.75-\mathrm{kb}$ ieI transcript is probably close to map unit $\mathbf{0 . 7 8 2}$. Therefore, the entire sequence between map units 0.797 and 0.780 was obtained by repeated determinations by the method of Maxam and Gilbert (21). The physical map for the restriction cleavage sites used for $3^{\prime}$ and $5^{\prime}$ end labeling of DNA fragments of $i e I$ is shown in Fig. 1. Figure 2 shows the nucleotide sequence of ieI, starting with the $5^{\prime}$ cap site of the $2.75-\mathrm{kb}$ mRNA close to map unit 0.796 and terminating $34 \mathrm{n}$ downstream of the polyadenylation signal AATAAA located at map unit $\mathbf{0 . 7 8 2}$.

Structural analysis of the $i e I$ gene. Structural analysis of the ieI gene was performed by nuclease digestion experiments with either 5' or ' $3^{\prime}$ end-labeled DNA fragments or uniformly labeled cRNA transcribed in vitro by SP6 RNA polymerase. The experimental strategy and results are shown in Fig. 3. Hybridization of IE RNA to labeled cRNA transcribed from map unit 0.769 (BamHI) to map unit 0.797 (DraI) (panel C, lane 6) revealed splicing. Protected fragments of 111,191 , 300 , and about $1,700 \mathrm{n}$ were detected. This finding was confirmed with smaller probes which were used to locate the exons precisely. A HindIII (0.787 map units)-PstI (0.790 map units) DNA fragment labeled at the $5^{\prime}$ end (panel A1) revealed a protected sequence of $521 \mathrm{n}$. A cRNA transcribed from map units 0.787 (HindIII) to 0.797 (DraI) (panel C, lane 5) showed the same 521-n fragment and also the three smaller fragments of 300,191 , and $111 \mathrm{n}$. A cRNA transcribed from map unit 0.787 (HindIII), which terminated already at map unit 0.794 (SacI) (panel C, lane 4), did not show the 300-n fragment, whereas the other fragments (521, 191 , and $111 \mathrm{n}$ ) remained detectable. This suggested that the 300-n fragment represents the first exon of the 2.75-kilobase (kb) IE mRNA and the large fourth exon starts $521 \mathrm{n}$ upstream of the single HindIII site in $i e I$, whereas the two exons of 111 and $191 \mathrm{n}$ should be located in between.

Hybridization of cRNA transcribed from map unit 0.787 (HindIII) to map unit 0.791 (XhoI) (panel C, lane 1) resulted in the 521-n fragment seen before and only one further fragment of $162 \mathrm{n}$, and it was concluded that the protected fragment of $162 \mathrm{n}$ represented a part of the 191-n exon. Therefore, the 191-n fragment should represent the third exon, which begins at a position of $29 \mathrm{n}$ upstream of the XhoI site close to map unit 0.791 and terminates $162 \mathrm{n}$ downstream.

The location of the 111-n second exon was mapped by $\mathrm{S} 1$ analysis with the small 160-n AccI restriction fragment located between map units 0.791 and 0.792 (panel A2). The fragment was labeled at both ends, and after separation each strand was used for sequencing and S1 analysis. After S1 digestion, protected fragments of 98 and 96 n were seen. cRNAs that terminated at the right $A c c$ I cleavage site (panel $C$, lane 2) failed to detect the 109- to 111-n fragment. The 191-n exon appeared to be heterogeneous in some determinations (panel $C$, lanes 2 and 5); the size heterogeneity of the second 111-n exon, however, was always found when cRNAs containing the sequences of this exon were used for hybridization (panel $\mathrm{C}$, lanes 4 to 6). A fragment size heterogeneity could be a technical artifact due to imprecise cleavage. However, this size heterogeneity could also occur in vivo since a T-rich region (nucleotides 1112 to 1123 , Fig. 2 ) is followed by a repeated splice acceptor site (AGAGAG) sequence. This exon could therefore start after the first or second AG dinucleotide. As shown below, this differential 
6ICGCAGICI ICGGICTGAC CACCGIAGAA CGCAGAGCIC CICGCIGCAG IAICCIGCCC AAGAAGGAGC GACCIICCCC GGCIACIGAA GCGCATCGGA CCCGCICGGI ICIAIIGGGA

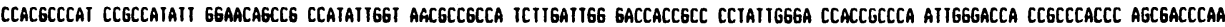

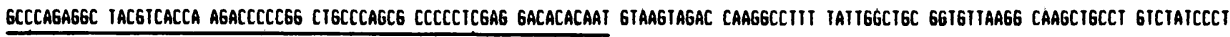

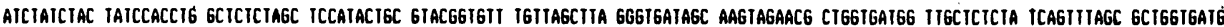

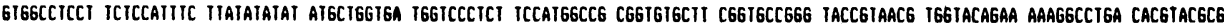

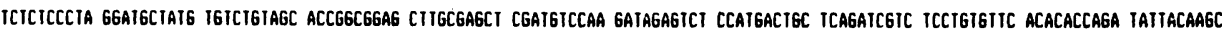

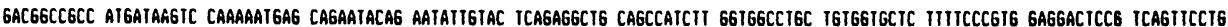

CGTGITGIIG CICGTACTGC GAAGAICICI CIIGCCCCGI CCTGAAAACC IAGGCCCIGA CAGAAAGAAG GGAGAGTIAG GAGAGGGCAC AGAGGAITCI GTCTGTGTCA AGGGGGCTIC

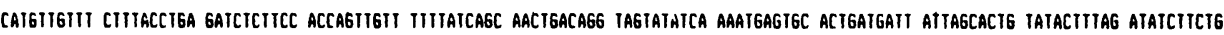

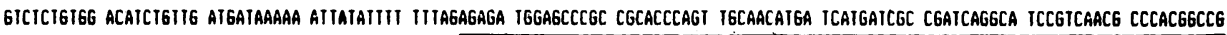

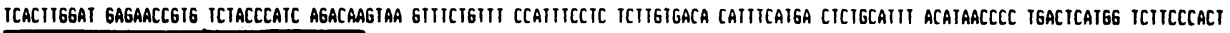

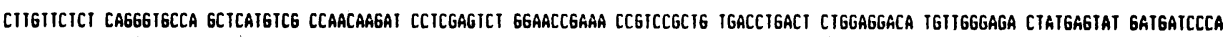

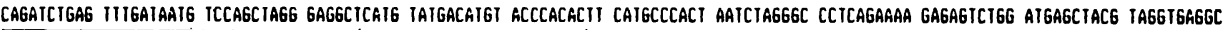

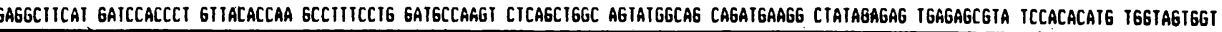

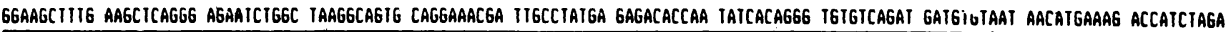

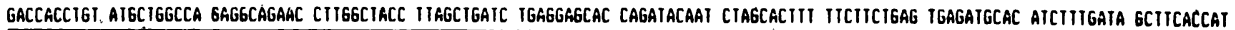

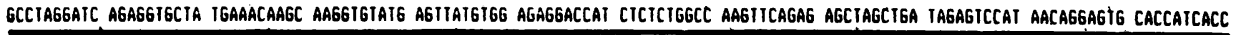

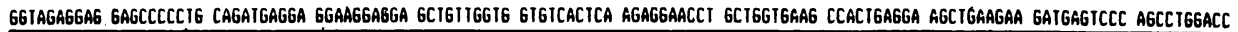

FIG. 2. Nucleotide sequence of $i e I$. The sequence shown starts with the $5^{\prime}$ cap site $(+1)$ of the $2.75-\mathrm{kb}$ mRNA (2) and extends $34 \mathrm{n}$ downstream of the AATAAA polyadenylation signal (boxed). The exon sequences are underlined, and the open reading frame, translated into the pp89, is indicated by a heavy line. The arrow shows the $3^{\prime}$ end of the $2.75-\mathrm{kb}$ mRNA. 

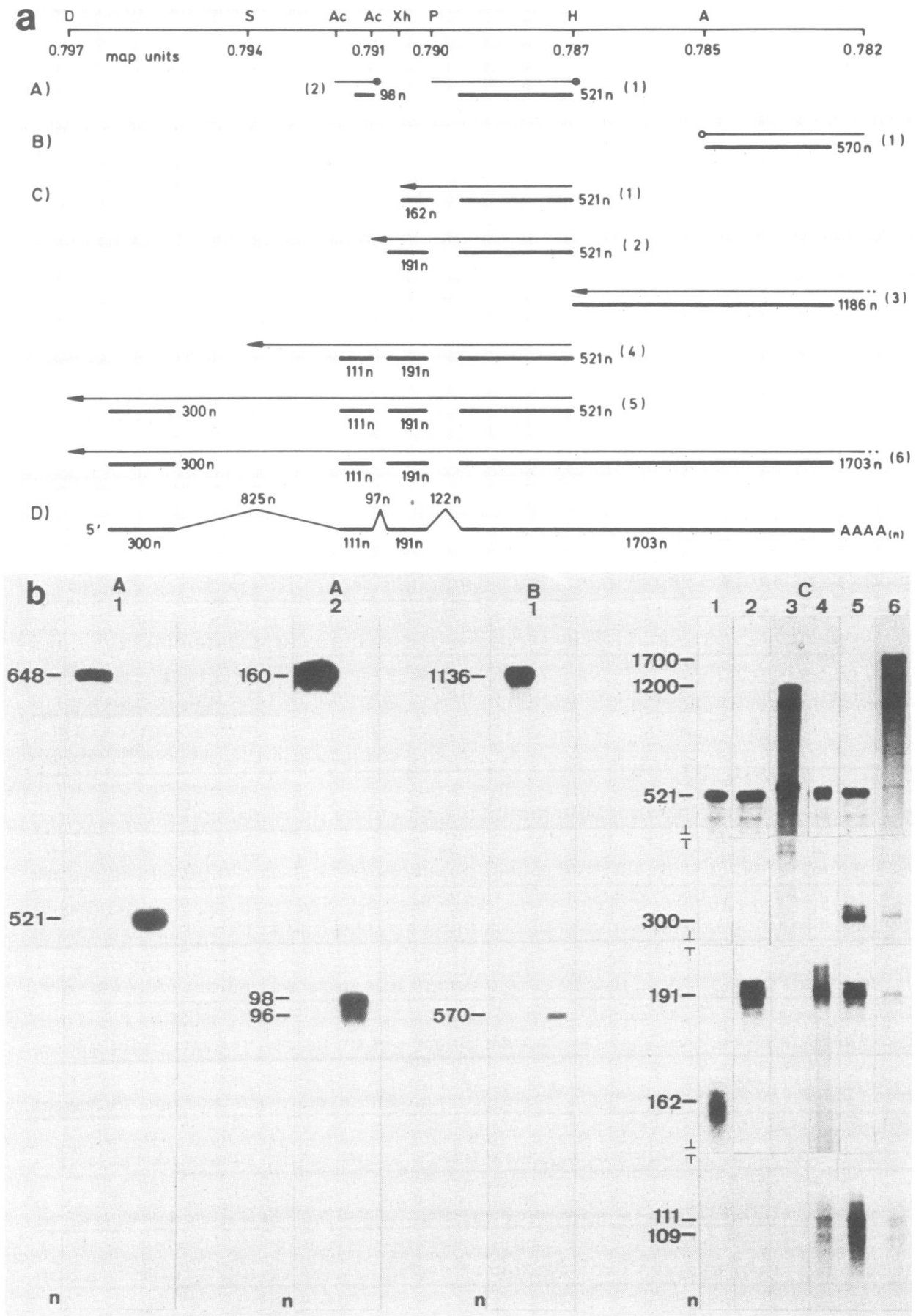

FIG. 3. Structural analysis of $i e$ I RNA. The experimental protocol for mapping of the $5^{\prime}$ and $3^{\prime}$ ends, as well as the locations of exons, is depicted in panel a, and experimental data are shown in panel $b$. To present all relevant information in one figure, the autoradiographs of some sequencing gels were cropped at identical positions and refitted as indicated (panel C, lanes 1 to 6). (a) Experimental protocol. IE RNA, hybridized to (i) 5'-labeled (A, closed circle) or 3'-labeled (B, open circle) DNA fragments or (ii) uniformly labeled cRNA (C, arrows indicate the direction and termination of cRNA transcription) were incubated with S1 nuclease (A and B) or RNases A and T1 (C). The cRNAs used in C, lines 3 and 6 , started at map units 0.780 and 0.769 , respectively. Solid bars show the locations of protected fragments, and the number of nucleotides is indicated. The results are summarized in D. The abbreviations used are the same as in Fig. 1. S, SacI. (b) Autoradiographs of protected fragments separated by electrophoresis in sequencing gels. Sequencing gels $(60 \mathrm{~cm})$ of $8 \%, 6 \%$, or $4 \%$ polyacrylamide were used. The sizes of labeled fragments before S1 nuclease treatment in A and B were taken from the sequence. When sequencing ladders served as size markers, the size of the protected fragments was determined by using $+1 n$ correction (6). Additional size markers were (i) from commercial suppliers and (ii) pBR322 DNA cleaved with HpaII. 
splicing would have no effect on the amino acid sequence of the protein. In conclusion, the second exon of $111 \mathrm{n}$ spans from $96 \mathrm{n}$ upstream to $15 \mathrm{n}$ downstream of the AccI site (map unit 0.792).

The 521-n fragment detected by cRNAs that started at map unit 0.787 (HindIII) was not found with cRNA that started at map unit 0.769 (panel $C$, lane 6), which revealed instead a protected fragment of about $1,700 \mathrm{n}$. cRNA transcribed from map unit $0.780(\mathrm{XbaI})$ to map unit 0.787 (HindIII) (panel C, lane 3) produced a protected fragment of about $1,200 \mathrm{n}$. Taken together, these results suggested that the fourth exon begins $521 \mathrm{n}$ upstream and terminates about $1,200 \mathrm{n}$ downstream of the HindIII site at map unit 0.787. An additional protected fragment of $530 \mathrm{n}$ (panel C, lane 3) probably represents products of transcription unit ie 3 (10). The analysis of this region is under study. To locate the $3^{\prime}$ end more precisely, $\mathrm{S} 1$ analysis was performed with a DNA fragment labeled at the $3^{\prime}$ end after cleavage with Asp 718 at map unit 0.785 and then digested with $X b a I$, which cleaved at map unit 0.780 . Hybridization of this fragment to IE RNA followed by digestion with nuclease $S 1$ resulted in a protected fragment of 570 nucleotides (panel B1). This result placed the 3 ' end of the fourth exon 23 n downstream of the AATAAA RNA polyadenylation consensus sequence (27). There was no indication of an additional exon within the major IE mRNA. Thus, the 2.75-kb IE mRNA coding for pp89 contains four exons of $300,111,191$, and $1,703 \mathrm{n}$ with a sum of $2.35 \mathrm{~kb}$. The sizes of the introns are 825,97 , and 122 n (Fig. 3D). The splice signals (Fig. 2) follow the AG-GT rule for splice junctions with the presence of $\mathrm{C}$ - or T-rich regions upstream of the AG dinucleotide splice acceptor sequence $(25,35)$ and the GTA $A$ AGT hexanucleotide at the splice donor sites $(25,35)$. The initiation and polyadenylation signals are also consistent with the respective eucaryotic transcription signals. In summary, ieI is a viral gene which uses the normal eucaryotic transcription signals for expression.

Deduced amino acid composition and predicted secondary structure of IE pp89. The sequence of the major IE mRNA, consisting of the four exons, contains an open reading frame of 1,785 $\mathrm{n}$ that starts with an AUG located within the second exon and terminates with a UGA. Differential splicing at the $5^{\prime}$ end of the second exon upstream of the first AUG therefore has no effect on the amino acid sequence of the protein. This open reading frame codes for a polypeptide of 595 amino acids (Fig. 4). It consists of 105 (17.6\%) acidic and $60(10.1 \%)$ basic amino acids. The $\mathrm{COOH}$ terminus is basic, followed by an acidic region, in which $51(38 \%)$ of 136 amino acids are $38 \mathrm{Glu}$ and 13 Asp. A similar acidic region is found at the $\mathrm{COOH}$ terminus of the HCMV major IE protein (37), where within 51 residues 22 are Glu and 2 are Asp. A second acidic region is found between amino acids 51 and 89 near the $\mathrm{NH}_{2}$ terminus, where within 39 amino acids 6 are Glu and 8 are Asp.

Comparisons of the ieI nucleotide and amino acid sequences with known eucaryotic viral and cellular sequences were carried out. No significant matches with viral proteins were found except a nuclear location signal found in polyomavirus and adenovirus $(17,18)$ located at the $\mathrm{COOH}$ terminus of pp89. The major IE proteins of HCMV and pp89 show similarities only in a Glu-rich part of the amino acid sequence. A total of 23 amino acids in the amino-terminal portion of pp89 were found to be identical with amino acids of the histone H2B consensus sequence. Identical amino acids at homologous positions were found in a region of 63 amino acids located in the amino-terminal part of both proteins.
Based on the amino acid sequence, the secondary structure of pp89 was predicted as described by Chou and Fasman (1) (Fig. 5). Based on this analysis, we have eliminated the introns and have recently been able to express the open reading frame in a vaccinia virus $(\mathrm{H}$. Volkmer et al., manuscript in preparation).

\section{DISCUSSION}

We have shown previously that gene ieI of MCMV is located between map units 0.781 and $0.796(10,11)$. The $5^{\prime}$ end of the 2.75-kb mRNA transcribed from ieI was mapped downstream of a long enhancer-promoter element and initiates with a 304-n nontranslated leader sequence 23 n downstream of the TATA box at the sequence GTCGCA (2). The first ATG is located at the $5^{\prime}$ end of the second 111-n exon, which is followed by the third 191-n exon. The major constituent of the mRNA is contributed by the 3 ' terminal exon of $1,703 \mathrm{n}$. It terminates $23 \mathrm{n}$ downstream of the consensus sequence for polyadenylation, AATAAA (27). This location of $i e I$ is in full agreement with data published before $(2,10,14)$. The splice donor and acceptor sequences follow the consensus sequences of other eucaryotic and viral mRNAs. The GT $\mathrm{G}_{\mathrm{A}}^{\mathrm{A}} \mathrm{AT}$ sequence was present at all three splice donor sites. No additional splice donor consensus sequence is present within ieI. A T- or C-rich region was always found $5^{\prime}$ to the splice acceptor sites $(25,35)$.

The amino acid sequence of pp89 was deduced from the mRNA sequence. The first AUG in the mRNA appears at $n$ 305 , a second is at $\mathbf{n} 332$, and a third is at $\mathrm{n} 338$. All three AUGs could represent the codon for the first amino acid of pp89 because they contain the consensus sequence for translation initiation, A/G NNATG (16). Since translation of most eucaryotic proteins starts at the first AUG, it is likely that the AUG at n 305 represents the codon for the $\mathrm{NH}_{2}$ terminal methionine of pp89. A single open reading frame extends from $n 305$ to $n$ 2,090, where a UGA stop codon is located. This $1,785-n$ open reading frame is translated into a protein of 595 amino acids with a calculated molecular weight of 66,713 . The distribution of charged amino acids and the phosphorylation of pp89 of MCMV are most probably responsible for overestimation of the molecular weight of pp89 after separation in denaturing sodium dodecyl sulfate-polyacrylamide gels. It should be noted that molecular weights of the HCMV major IE protein (37), ICP4 (Vmw 175) (22), and IE110 of HSV-1 (26) have also been overestimated. In all three IE proteins the apparent molecular weight is, as with pp89, about 1.3 -fold higher than the calculated molecular weight.

pp89 is a nuclear protein and should therefore contain nuclear location signals. A nuclear location signal has been defined for the simian virus 40 large-T protein and consists of a stretch of predominantly basic amino acids (Pro-Lys-LysLys-Arg-Lys-Val) located in the amino-terminal part of the protein $(18,34)$. This sequence appears to represent a prototypic nuclear location signal also found in other viral proteins (36). pp89 contains a similar sequence (Pro-LysLys-Lys-Ser-Lys-Lys) located at the carboxy terminus. The possibility that such a sequence functions as a nuclear location signal is derived from deletion studies of a similar sequence present in the carboxy termini of the E1A proteins of adenovirus 5, which resulted in a reduced rate of nuclear accumulation (17). We therefore suggest that this sequence represents the nuclear location signal of pp89.

In contrast to the gene coding for ICP4 of herpes simplex virus, which is transcribed into an unspliced mRNA (22), the 
Het Glu Pro Ala Ala Pro Ser Cys Asn Met lle Met Ile Ala Asp 6ln Ala Ser Val Asn Ala His Gly Arg His Lee Asp Glu Asn Arg 20

Val Tyr Pro Ser Asp Lys Val Pro Ala His Val Ala Asn Lys lle Leu Glu Ser Gly Thr Glu Thr Val Arg Cys Asp Leu Thr Leu Glu 60

Asp Het Leu 6ly Asp Tyr Glu Tyr Asp Asp Pro Thr Glu Glu Glu Lys lle Leu Met Asp Arg lle Ala Asp His Val gly Asn Asp Asn 90

Ser Asp Met Ala lle Lys His Ala Ala Val Arg Ser Val Leu Leu Ser Cys Lys lle Ala His Leu Met lle Lys 6la Asn Tyr 6ln Ser 120

Ala Ile Asn Ser Ala thr Asn Ile Leu Cys Gln Leu Ala Asn Asp Ile Phe 6lu Arg lle Glu Arg Gin Arg Lys Met Ile Tyr 6ly Cys 150

Phe Arg Ser 6lu Phe Asp Asn Val 6ln Leu 6ly Arg Leu Met Jyr Asp Met Tyr Pro His Phe Met Pro Thr Asn Leu 61y Pro Ser 6lu 180

Lys Arg Val Irp Met Ser Tyr Val Gly Glu Ala lle Val Ala Ala Thr Asn lle Asp His Ala Leu Asp Glu Arg Ala Ala Irp Ala Lys 210

Thr Asp Cys Ser Leu Pro gly Glu Phe Lys Pro 6lu Leu Cys Val Leu Val Gly Ala lle Arg Arg Leu His Asp Pro Pro Cys Tyr Thr 240

Lys Pro Phe Leu Asp Ala Lys Ser 6ln Leu Ala Val Trp 6ln Gin Met Lys Ala lle Glu Ser 6lu Ser Val Ser Thr His Val Val Val 270

Val glu Ala Leu Lys Leu Arg glu Asn Leu Ala Lys Ala Val Gln Glu Thr lle Ala Tyr Glu Arg His Gin Tyr His Arg Val Cys 6ln 300

Met Met Cys Asn Asn Met Lys Asp His Leu Glu Thr Thr Cys Met Leu Ala Arg Gly Arg Thr Leu Ala Thr Leu Ala Asp Leu Arg Ser 330

Thr Arg Tyr Asn leu Ala Leu Phe Leu Leu Ser Glu Met His lle Phe Asp Ser Phe Thr Met Pro Arg Ile Arg Gly Ala Met Lys Gln 360

Ala Arg Cys Met Ser Tyr Val Glu Arg Thr lle Ser Leu Ala Lys Phe Arg 6lu Leu Ala Asp Arg Val His Asn Arg Ser Ala Pro Ser 390

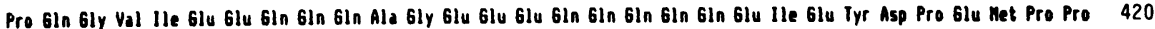

Leu Glu Arg 6lu glu glu 6ln glu Asp glu gln Val glu glu Glu Pro Pro Ala Asp glu glu glu Gly Gly Ala Val gly gly Val thr 450

Gln Glu glu Pro Ala gly glu Ala Thr Glu glu Ala glu Glu Asp Glu Ser Gln Pro gly Pro Ser Asp Asn 6ln Val Val Pro glu Ser 480

Ser 6lu Thr Pro Thr Pro Ala glu Asp glu glu Thr Gln Ser Ala Asp Glu Gly Glu Ser Gin Glu Leu Glu Gly Ser Gin Gin Leu lle 510

Leu Ser Arg Pro Ala Ala Pro Leu Thr Asp Ser glu Thr Asp Ser Asp Ser glu Asp Asp Asp Glu Val Thr Arg lle Pro Val 6ly Phe 540

Ser Leu Met Thr Ser Pro Val Leu Gla Pro Thr Thr Arg Ser Ala Thr Ala Ala Ala Ser Ser 6ly Thr Ala Pro Arg Pro Ala Leu Lys 570

Arg 6lin Tyr Ala het Val His Thr Arg Ser Lys Ser Ser 6lu Asn 6ln 6ln 6ln Pro Lys Lys Lys Ser Lys. Lys.

FIG. 4. Deduced amino acid sequence of IE pp89. Broken line, homology to HCMV major IE protein; dotted line, homology to simian virus 40 large $\mathrm{T}$ antigen; solid line, region homologous to histone H2B. Solid bars indicate identical amino acids at the same position in both proteins, and open bars indicate conservative amino acid exchanges (comparison with histone H2B) that do not affect the polarity or charge of the protein.

major IE gene in both MCMV and HCMV (37) contains four exons. In both viruses the first exon is nontranslated, the second exon starts with the first ATG, and the fourth exon is the major component of the mRNA. In addition, the functions of both gene products seem to be very similar $(4,14)$. Remarkably, there was no significant homology between the nucleotide sequences of these genes. Also, after comparing the protein sequences, only one region with homology extending over more than 8 amino acids was found in a Glu-rich part of both IE proteins, where amino acids 424 to 434 of pp89 and 426 to 437 of the major IE protein of HCMV share 8 of 12 amino acids.

A notable similarity was found between amino acids 27 to 87 of the histone H2B consensus sequence (39) and amino acids 96 to 153 of pp89. In this region, 23 (37\%) of 63 amino acids were found to be identical and located at a correspond- ing position in the amino acid sequence. The codons for these 23 amino acids display $83 \%$ identity, whereas only $48 \%$ homologous nucleotides would be required to encode these amino acids. The similarity within this region increases to $62 \%$ when conservative amino acid exchanges are considered as similar. The H2B proteins of different species maintain a high degree of sequence conservation in certain regions of the polypeptide, including amino acids 67 to 73 (Asn-Asp-Ile-Phe-Glu-Arg-Ile), which are represented in an identical sequence in pp89 (amino acids 134 to 140). The region between residues 37 and 114 of $H 2 B$ is important for the interaction of $\mathrm{H} 2 \mathrm{~B}$ with histone $\mathrm{H} 2 \mathrm{~A}(8,9)$. It could be speculated that this region in pp89 plays a role in an interaction of IE pp89 with cellular chromatin.

After transfection of the DNA sequences which encode pp89, the lymphocyte-detected IE antigen (LYDIEA) (32) 


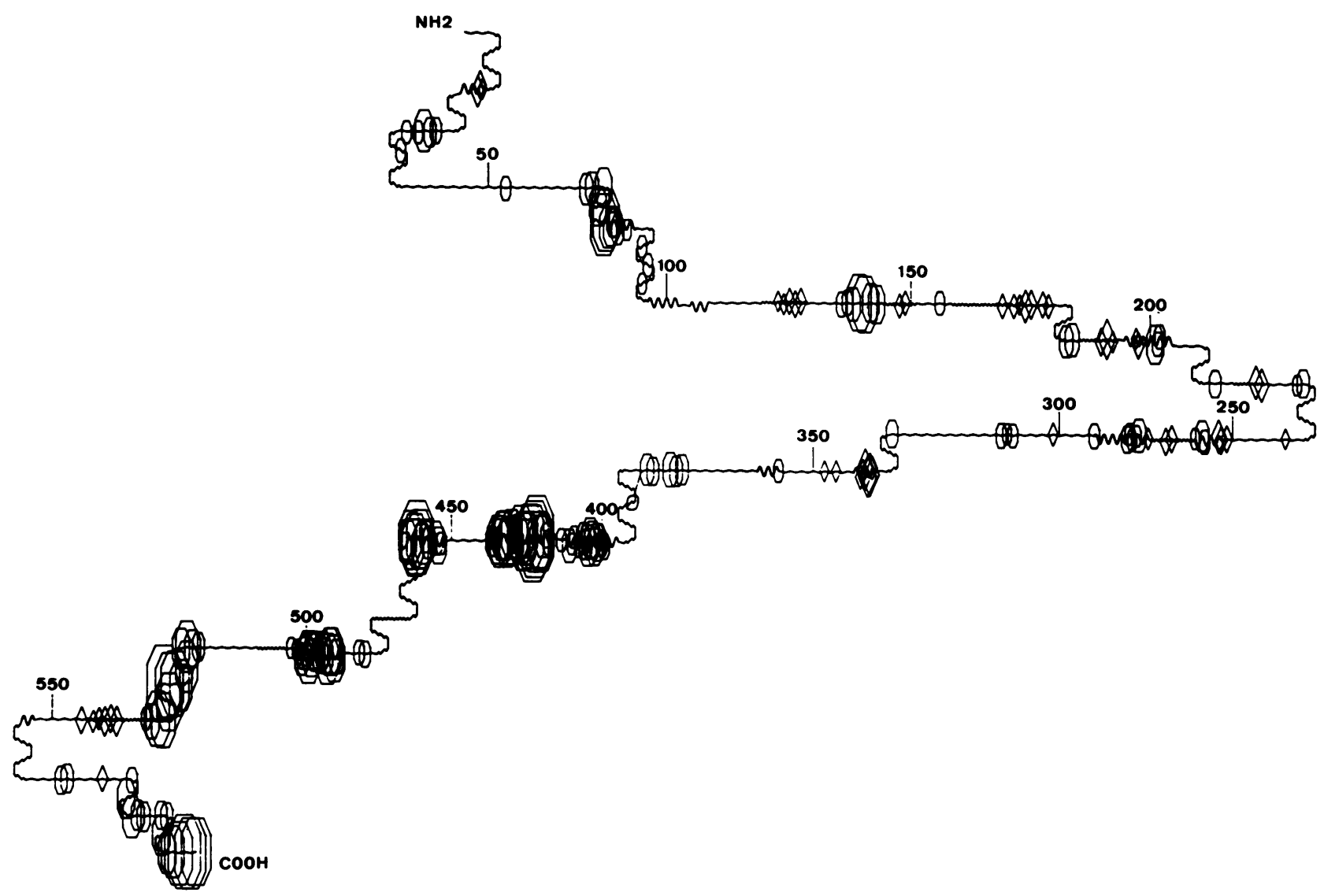

FIG. 5. Secondary structure of IE pp89. The method of Chou and Fasman (1) was used. Octagons indicate regions of hydrophilicity of $>0.7$, and rhombic symbols stand for regions of hydrophobicity of $<-0.7$.

was found to be expressed (15). The only other herpesviral protein reported to play a role in the host response to herpesviral infection is LYDMA, an antigen detected by specific $\mathrm{T}$ lymphocytes on Epstein-Barr virus-transformed cells. It is thought that LYDMA is a part of the latentinfection membrane protein. Analysis of the amino acid sequence of the latent-infection membrane protein predicted repeated hydrophobic regions separated by hydrophilic segments, an arrangement indicative of membrane insertion $(5$, 19). The predicted amino acid sequence of $\mathrm{pp} 89$, however, does not contain such regions, and there is no evidence for membrane-spanning domains. Thus, pp89 is structurally different from the Epstein-Barr virus latent-infection membrane protein, and pp89 probably requires processing for expression at the cell membrane. The absence of structural characteristics that indicate cell surface expression does not contradict the immunological findings. Nonglycosylated internal viral proteins can reach the cell membrane by alternative routes of processing and degradation (24). The known features of pp89 appear similar to some properties of a simian virus 40 nonstructural protein, the large- $T$ antigen. Similar to pp89, simian virus 40 large-T antigen is a phosphoprotein involved in regulation of simian virus $\mathbf{4 0}$ genes. The majority of simian virus 40 large-T antigen in the cell is concentrated in the nucleus, but a small amount of the protein is present on the cell surface, probably after acylation (13). Surface-expressed simian virus 40 large-T antigen serves as a target structure for CTL (38). Work is in progress to study the surface expression of $\mathrm{pp89}$.

\section{ACKNOWLEDGMENTS}

This study was supported by grant Ko 571/8 from the Deutsche Forschungsgemeinschaft and by grant PTB 8614 from the Bundesministerium für Forschung und Technologie.

We thank A. Klug for comments, H. Niller and W. Bodemer for technical help, S. Modrow for secondary-structure analysis, B. Mächtig, G. Röhrs, and M. Votteler for technical assistance, and S. Grau for manuscript preparation.

\section{LITERATURE CITED}

1. Chou, P. Y., and G. D. Fasman. 1974. Prediction of protein conformation. Biochemistry 13:222-245.

2. Dorsch-Häsler, K., G. M. Keil, F. Weber, M. Jasin, W. Schaffner, and U. H. Koszinowski. 1985. A long and complex enhancer activates transcription of the gene coding for the highly abundant immediate early mRNA in murine cytomegalovirus. Proc. Natl. Acad. Sci. USA 82:8325-8329.

3. Ebeling, A., G. M. Keil, E. Knust, and U. H. Koszinowski. 1983. Molecular cloning and physical mapping of murine cytomegalovirus DNA. J. Virol. 47:421-433.

4. Everett, R. D. 1984. Trans activation of transcription of herpes virus products: requirement for two HSV-1 immediate-early polypeptides for maximum activity. EMBO J. 3:3135-3141.

5. Fennewald, S., V. van Santen, and E. Kiefi. 1984. Nucleotide sequence of an mRNA transcribed in latent growth-transforming virus infection indicates that it may encode a membrane protein. J. Virol. 51:411-419.

6. Green, M. R., and R. G. Roeder. 1980. Definition of a novel promoter for the major adenovirus-associated virus mRNA. Cell 22:231-242.

7. Honess, R. W., and B. Roizman. 1974. Regulation of herpesvirus macromolecular synthesis. I. Cascade regulation of the synthe- 
sis of at least three groups of viral proteins. J. Virol. 14:819.

8. Isenberg, I. 1979. Histones. Annu. Rev. Biochem. 48:159-191.

9. Kedes, L. H. 1979. Histone genes and histone messengers. Annu. Rev. Biochem. 48:837-870.

10. Keil, G. M., A. Ebeling-Keil, and U. H. Koszinowski. 1987. Immediate-early genes of murine cytomegalovirus: location, transcripts, and translation products. J. Virol. 61:526-533.

11. Keil, G. M., A. Ebeling-Keil, and U. H. Koszinowski. 1984. Temporal regulation of murine cytomegalovirus transcription and mapping of viral RNA synthesized at immediate early times after infection. J. Virol. 50:784-795.

12. Keil, G. M., M. R. Fibi, and U. H. Koszinowski. 1985. Characterization of the major immediate-early polypeptides encoded by murine cytomegalovirus. J. Virol. 54:422-428.

13. Klockmann, U., and W. Deppert. 1983. Acylated simian virus 40 large $T$ antigen: a new subclass associated with a detergentresistant limina of the plasma membrane. EMBO J. 2:11511157.

14. Koszinowski, U. H., G. M. Keil, H. Volkmer, M. R. Fibi, A. Ebeling-Keil, and K. Münch. 1986. The 89,000- $M_{\mathrm{r}}$ murine cytomegalovirus immediate-early protein activates gene transcription. J. Virol. 58:59-66.

15. Koszinowski, U. H., M. J. Reddehase, G. M. Keil, and J. Schickedanz. 1987. Host immune response to cytomegalovirus: products of transfected viral immediate-early genes are recognized by cloned cytolytic T lymphocytes. J. Virol 61:2054-2058.

16. Kozak, M. 1983. Comparison of initiation of protein synthesis in procaryotes, eucaryotes, and organelles. Microbiol. Rev. 47:145.

17. Krippl, B., B. Ferguson, N. Jones, M. Rosenberg, and $\mathbf{H}$. Westphal. 1985. Mapping of functional domains in adenovirus E1A proteins. Proc. Natl. Acad. Sci. USA 81:6988-6992.

18. Lanford, R. E., and J. S. Butel. 1984. Construction and characterization of an SV40 mutant defective in nuclear transport of T antigen. Cell 37:801-813.

19. Liebowitz, D., D. Wang, and E. Kieff. 1986. Orientation and patching of the latent infection membrane protein encoded by Epstein-Barr virus. J. Virol. 58:233-237.

20. Maniatis, T., E. F. Fritsch, and J. Sambrook. 1982. Molecular cloning: a laboratory manual. Cold Spring Harbor Laboratory, Cold Spring Harbor, N.Y.

21. Maxam, A. M., and W. Gilbert. 1980. Sequencing with base specific chemical cleavages. Methods Enzymol. 65:499-560.

22. McGeoch, D. J., A. Dolan, S. Donald, and D. H. K. Brauer. 1986. Complete DNA sequencing of the short repeat region in the genome of herpes simplex virus type 1 . Nucleic Acids Res. 14:1727-1745.

23. Melton, D. A., P. A. Krieg, M. R. Rebagliati, T. Maniatis, K. Zinn, and M. R. Green. 1984. Efficient in vitro synthesis of biologically active RNA and RNA hybridization probes from plasmids containing a bacteriophage SP6 promoter. Nucleic Acids Res. 12:7035-7056.

24. Mills, K. H. G. 1986. Processing of viral antigens and presenta- tion to class II restricted T cells. Immunol. Today 7:260-263.

25. Mount, S. M. 1982. A catalog of splice junction sequences. Nucleic Acids Res. 10:459-472.

26. Perry, L. J., F. R. Rixon, R. D. Everett, M. C. Frame, and D. J. McGeoch. 1986. Characterization of the IE110 gene of herpes simplex virus type 1. J. Gen. Virol. 67:2365-2380.

27. Proudfoot, N. J., and G. G. Brownlee. 1976. 3' Non-coding region sequences in eucaryotic messenger RNA. Nature (London) 263:211-214.

28. Reddehase, M. J., H.-J. Bühring, and U. H. Koszinowski. 1986. Cloned long-term cytolytic T-lymphocyte line with specificity for an immediate-early membrane antigen of murine cytomegalovirus. J. Virol. 57:408-412.

29. Reddehase, M. J., M. R. Fibi, G. M. Keil, and U. H. Koszinowski. 1986. Late-phase expression of a murine cytomegalovirus immediate-early antigen recognized by cytolytic T lymphocytes. J. Virol. 60:1125-1129.

30. Reddehase, M. J., G. M. Keil, and U. H. Koszinowski. 1984. The cytolytic $\mathrm{T}$ lymphocyte response to the murine cytomegalovirus. I. Distinct maturation stages of cytolytic $\mathrm{T}$ lymphocytes constitute the cellular immune response during acute infection of mice with the murine cytomegalovirus. J. Immunol. 132: $482-489$.

31. Reddehase, M. J., G. M. Keil, and U. H. Koszinowski. 1984. The cytolytic $\mathrm{T}$ lymphocyte response to the murine cytomegalovirus. II. Detection of virus replication stage-specific antigens by separate populations of in vivo active cytolytic T lymphocyte precursors. Eur. J. Immunol. 14:56-61.

32. Reddehase, M. J., and U. H. Koszinowski. 1984. Significance of herpesvirus immediate early gene expression in cellular immunity to cytomegalovirus infection. Nature (London) 312:369371.

33. Reddehase, M. J., F. Weiland, K. Münch, S. Jonjic, A. Lüske, and U. H. Koszinowski. 1985. Interstitial murine cytomegalovirus pneumonia after irradiation: characterization of cells that limit viral replication during established infection of the lungs. J. Virol. 55:264-273.

34. Richardson, W. D., B. L. Roberts, and A. E. Smith. 1986. Nuclear location signals in polyoma virus large-T. Cell 44:7785.

35. Sharp, P. A. 1981. Speculations on RNA splicing. Cell 23:643646.

36. Smith, A. E., D. Kalderon, B. L. Roberts, W. D. Colledge, M. Edge, P. Gillett, A. F. Markham, E. Paucha, and W. D. Richardson. 1985. The nuclear location signal. Proc. R. Soc. Lond. B Biol. Sci. 226:43-58.

37. Stenberg, R. M., D. R. Thomsen, and M. F. Stinski. 1984. Structural analysis of the major immediate early gene of human cytomegalovirus. J. Virol. 49:190-199.

38. Tevethia, S. S., D. C. Flyer, and R. Tjian. 1980. Biology of simian virus 40 (SV40) transplantation antigen ( $\mathrm{TrAg})$. Virology 107:13-23.

39. Wells, D. E. 1986. Compilation analysis of histones and histone genes. Nucleic Acids Res. 14:119-149. 